\title{
Deciphering Disparities in Childhood Stunting in an Underdeveloped State in India: an Investigation Applying the Unconditional Quantile Regression Method
}

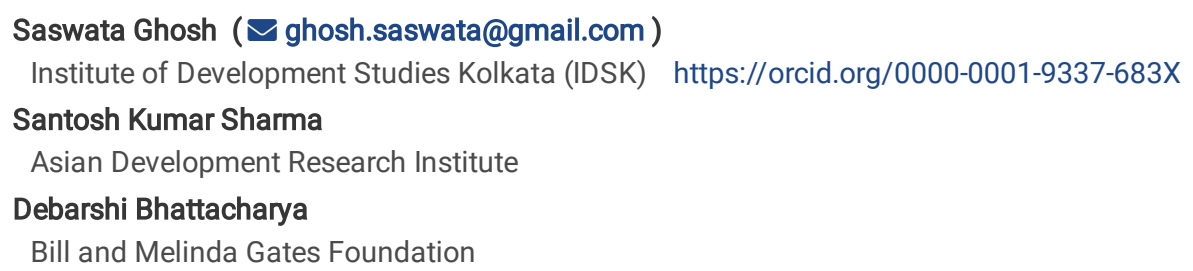

Research article

Keywords: Childhood stunting, Unconditional quantile regression, Counterfactual decompositions, Bihar, India

Posted Date: August 18th, 2020

DOI: https://doi.org/10.21203/rs.3.rs-50613/v1

License: (c) (i) This work is licensed under a Creative Commons Attribution 4.0 International License. Read Full License

Version of Record: A version of this preprint was published at BMC Public Health on October 16th, 2020. See the published version at https://doi.org/10.1186/s12889-020-09559-8. 


\section{Abstract}

\section{Background}

Unacceptably high rate of childhood stunting for decades remained a puzzle in the eastern Indian state of Bihar. Despite various programmatic interventions, nearly half of the under-five children (numerically about 10 million) are still stunted in this resource-constrained state.

\section{Data and Methods}

Using four successive rounds of National Family Health Survey (NFHS) data spread over more than two decades and by employing quantile regressions and counterfactual decomposition (QR-CD), the present study aims to assess effects of various endowments as well as returns to those endowments in disparities in childhood stunting over the period.

\section{Results}

The results show that although child's height-for-age Z-scores (HAZ) disparity was largely accounted for differing levels of endowments during earlier decade, in the later periods, inadequate access to the benefits from various development programmes was also found responsible for HAZ disparities. Moreover, effects of endowments and their returns vary across quantiles. We argue that apart from equalizing endowments, ensuring adequate access to different nutrition-centric programmes are essential to lessen the burden of childhood stunting.

\section{Conclusion}

The state must focus on intersectoral convergence of different schemes in the form of state nutrition mission, and, strengthen nutrition-centric policy processes and their political underpinnings to harness better dividend.

\section{Background}

Child undernutrition in India has remained a priority among academician and policy makers. Despite significant economic growth during past two decades, prevalence of childhood stunting has dropped only by 27 percent (about 14 points) [1]. UNICEF (2013) has observed that India alone contributed 38 percent of the stunted children in the world in 2011 [2], while Headey [2013] estimated that number of undernourished children in India was higher than in all of Africa [3]. Jose et al. emphasized that despite a moderate decline in child undernutrition during past decade, a large and graded socio-economic disparity in child undernutrition continues to exist [4]. A systematic review on prevalence of child undernutrition in India has also concluded that burden of child undernutrition is still unacceptably high in India and there is an urgent need to understand the risk factors in greater details [5]. It is needless to mention that a rapid reduction of child undernutrition in India is imperative to lessen global burden of child malnutrition.

Majority of the studies carried out in India and other developing countries have demonstrated that an array of household, individual, and contextual factors have significant bearing on childhood undernutrition [6-7]. Higher consumption expenditure in household lowers the risk of child malnutrition [6-7], while economic gradients contribute in maintaining vicious cycle of poverty and malnutrition [8-10]. Lack of household sanitation [11-12], low body-mass index (BMI) among mothers [13-15], less parental education [16]; lack of bargaining power of women within households [17] significantly and negatively affect child's anthropometric outcomes in low- and middle-income countries.

Recent studies found that women's BMI, education, child's adequate diet, household asset, and sanitation, age at marriage, antenatal care and household size are strong and significant predictors of childhood anthropometric outcomes and explains much of the variations across the districts in India [18-19]. Jose et al. have noted that about 83 percent of high stunting prevalence (higher than the national average) districts belong to the eight states located in the north-central, western, and eastern region [4]. Thus, effects of endowments (or covariate per se) were found to be significant; however, they vary across space and nature of endowment.

At the same time, some studies have also attempted to document disparities in returns to endowments (or strength of association per se) and their different dimensions, which potentially influence child nutritional outcomes. For example, how quality of the governance, institutional strength in implementing public policies, reach of public services, bargaining power of the communities, and macro-level political economic context etc. could influence health and nutritional outcomes have been documented in these studies. In Indian context, disparity in institutional performance (measured in terms of quality of public services such as health, education and public distribution system) was observed between northern and north-central states, and southern states [20-22]. Harriss and Kohli investigated influence of inter-state political and institutional factors on child undernutrition and differentiated between the politics of "clientelism" and "programmatic" politics [23]. They argued that such political spectrum could impinge on worse and better child anthropometric outcomes respectively. Significant gaps in implementation regarding nature, coverage and quality of Integrated Child Development Services (ICDS) were found by various researchers in different states [24-27]. Using conditional quantile regression model, Mukhopadhyay (2013) found that while the presence of government facilities was able to make a positive difference in upliftment of nutritional status for the relatively better-off children in India, they had not benefitted the worse affected children much [28]. 
Majority of literature reviewed above have either tried to identify some of the key observable characteristics (or covariates or endowments) that help in explaining variation in child anthropometric outcomes or have emphasized differential strength of relationship (or coefficients or returns to endowments) might also influence childhood nutritional outcomes. Only a few studies have attempted to quantify the contribution of sociodemographic, economic and ecological variables, individually or at the aggregate (covariate effects) and contribution of the strength of relationship (or coefficient effects) together in the South Asian context $[29,40]$. In the present context, covariate effects can be defined as the differences in nutrition outcomes across periods explained by the differences in observed covariates. On the other hand, differences explained by differing strengths of relationships between covariates and outcomes, in other words the "returns" to specific endowments, can be termed coefficient effects. To find out differentials in child undernutrition in Nepal and Bangladesh, Srinivasan et al. have highlighted that rural-urban disparities in child nutrition are primarily attributable to the difference in the levels of critical endowments such as household affluence, maternal as well as spouse's education, while differences in the strength of association (or returns to endowments) between determinants and nutrition outcomes are of relatively small in magnitude [29]. However, studies conducted in India found that large disparities in child nutritional outcomes across states are modestly explained by the differences in critical endowments, while returns to endowments or implementation of nutrition-relevant policies and programmes play an important role in explaining such disparity [30].

During past two decades, India and its states have witnessed substantial changes in endowments (covariates) and also experienced enormous policy changes (coefficients) which could have direct or indirect bearing on child nutritional outcomes. Apart from expanding scope and coverage of ICDS, many states have also come up with many state-specific schemes and emphasized multisectoral nutrition intervention. For example, Maharashtra, Madhya Pradesh and Karnataka have implemented State Nutrition Missions and placed special emphasis on nutrition surveillance, district planning, and district-level monitoring with the goal of reducing undernutrition at a desirable extent.

The present study intends to find out changing relative contribution of different covariates and coefficients resulting disparities in childhood stunting in different intervals between 1992-93 and 2015-16 in the state of Bihar. The state of Bihar, located in the eastern part of India and a resourceconstrained state, having the highest prevalence of childhood stunting in India for several past decades. The proportion of childhood stunting has declined by 21 percent (or by 13 percentage-points) during last twenty years - implying an annual average decline of just one percent [1]. Numerically, about 10 million children in Bihar are stunted. Notably, Bihar alone contributes around 15 percent of stunted children in India. More importantly, out of 100 districts, where prevalence of stunting is the highest, one-quarter belonging to Bihar. It was estimated that malnutrition (maternal and child malnutrition together) continued to be the largest risk factor driving the most death and disability since 1990s [31].

Changes in the basic socio-demographic and economic indicators during last two decades are given in Table 1. To note, the state of Bihar has undergone territorial changes following Bihar Reorganization Act (2000) (Government of India, 2000) and a separate state of Jharkhand was created from the districts of south Bihar.

\section{$--<$ Table 1: Some important demographic and health indicators of Bihar in 1992-93 and 2015-16>-}

The study contributes to the literature of childhood stunting by applying a recently developed advanced statistical technique, namely, quantile regression-based counterfactual decomposition (QR-CD) method, which allows a more nuanced approach to disentangle the effects of endowments (or covariates) and returns to endowments (or coefficients). The study would also like to enquire whether changing contribution of covariate and coefficient effects are different at the lower tail of the distribution of height-for-age z-scores (HAZ), where severe stunting is likely to be prevalent, compared to the middle and higher tail. Such insights would be of utmost value in a policy atmosphere where targeting most vulnerable is considered imperative. The primary hypothesis is that the period-wise changes across the HAZ distribution arises from covariate, rather than coefficient effects. Disparities at the lower tail of the distribution is of particular interest of the present study. A secondary hypothesis is that, even if a covariate or a coefficient dominates, there are important differences across the HAZ distribution in the relative contributions of covariate and coefficient effects to period-wise changes.

\section{Methods}

\section{Data and Variables}

Data for this study are obtained from the four rounds of National Family Health Survey (NFHS), an Indian variant of Demographic and Health Surveys (DHS), which were carried out between 1992-93 and 2015-2016 by the IIPS, Mumbai; ORC Macro; Macro International Inc and ICF [1, 41-43]. It is imperative to note that although the state of Bihar was reorganized in 2000, data were culled out for the second round (1998-99) for the districts representing present-day Bihar using district codes to make it comparable with third round (2005-06). During 1992-93, in undivided Bihar, the survey collected information of 3,575 children born during the four years preceding the survey. During 1998-99, 2005-06 and 2015-16 information of 2,948; 2,320 and 3,679 children were collected respectively. During 1998-99 and 2005-06 information were collected for the children born during three years preceding the survey, while such duration was for five years during 2015-16. For this reason, the study has been restricted for the children of age group $0-36$ months in order to compare childhood stunting over the four rounds of NFHS. It may be noted that the present study intends to compare changes of covariate and coefficient effects between two successive rounds such as between NFHS 1 and NFHS 2; NFHS 2 and NFHS 3; and; NFHS 3 and NFHS 4, and not over the rounds, for instance, between NFHS 1 and NFHS 4. 
Stunting has been defined as height-for-age Z scores (HAZ) less than minus two standard deviation of the WHO International Reference Standard [45]. It is universally considered as a standard indicator of child undernutrition and health status as it reflects chronic undernutrition caused by long-term deprivation. A child's height-for-age is a measure of their height, relative to a healthy standard population of the same sex and the same age-inmonths. Height-for-age is measured using z-scores, meaning that it is expressed as a difference between the height of the observed child and the average height of healthy children, scaled by the standard deviation of child height in the healthy population. A child with a height-for-age z-score (HAZ) of zero would be as tall as the average child in the healthy reference population; a child with a negative height-for-age z-score is shorter than the average child in the healthy reference population. The formula for calculating the HAZ score is

$$
\mathrm{HAZ}=\frac{\text { Observed hight-avarage hight }}{\text { Statndard Deveiation (SD) }}
$$

Complete information on HAZ score was available for 1,$821 ; 1,627 ; 1,188$; and, 2,184 of aged $0-36$ months in the four respective rounds. HAZ has been used as outcome variable in all the regression models. The study has included current age of the child (in months), square of the age, sex of the child (male, female), size of the child at birth (more than average, average, small) as a proxy for birth weight, initiation of early breastfeeding (no, yes), and number of siblings as child characteristics. Receipt of any services from ICDS during 12 months preceding the survey was included while comparing NFHS 3 and 4 because such information was available only in these rounds. Maternal characteristics comprises age of the mother at first birth (in years), maternal education (in completed years), work status (working, not-working), degree of media exposure (additive index of three binary variables - reading newspaper, watching television, listening radio at least once a week). Institutional delivery (no, yes) was considered as a proxy of contact with health personnel by mother. Maternal height and maternal BMI, and anaemia (no, mild, moderate and severe) were included for analyses of second, third and fourth rounds of NFHS because such information were not collected in the first round. Similarly, normalized factor scores of variables indicating household decision making, freedom of movement etc. were incorporated as maternal level variable in second, third and fourth rounds of NFHS (see endnote 1).

Household wealth index, religious category (Hindu, Muslims/others), membership to social group (scheduled castes (SC), scheduled tribes (ST), Others) were incorporated as household level variables. It may be mentioned here that the first round of NFHS did not collect data on 'other backward castes' (OBCs) and thus categorised in 'Others'. Household wealth index as calculated by DHS is based on possession of household durable assets, availability of safe drinking water and sanitation, and handholding. For construction of index, the variables were first broken into sets of dichotomous variables and indicator weights are assigned using principal component analyses (PCA) as suggested by Filmer and Pritchett [32]. In addition to the variables representing child, maternal and household characteristics, place of residence (rural/urban) was also included in the regression models.

\section{Statisticalanalysis}

To assess the differentials in HAZ scores over the study period, first, the distribution of the HAZ scores of Bihar's children was estimated separately in each survey period using kernel smoothing techniques and period-wise differentials were computed at each quantile to provide raw difference in HAZ scores across distribution.

One of the primary objectives of the present study was to decompose the period-wise differences in child's HAZ scores in covariate effect, i.e. the differences in HAZ scores arising out of the differences in levels of characteristics or composition of the children in the survey-period; and the coefficient effect, i.e. the differences in HAZ scores were caused by the differences in the returns to those characteristics or structure, across the entire HAZ distribution. It is worth mentioning that majority of the earlier studies have largely modelled the nutrition outcomes (such as HAZ scores) at the mean level by using ordinary least square (OLS), or the prevalence of stunting, underweight or wasting by using logit or probit regression approaches. Limitation of these approaches is related to the fact that changes in covariates and the effect of covariates is constrained to be same along the entire distribution of outcome variable. Further, decompositions based on OLS would apply only to the period-wise mean differences in HAZ scores; however, not to other distributional characteristics, such as quantiles.

Quantile regression (QR) method, developed by Koenker and Bassett, allows effects of covariates to vary across the entire distribution of continuous response variable [33]. Limitation of this model is that it estimates only the conditional quantile effects of changes in covariates. In the present study, we were interested to estimate the effect of policy intervention, for instance, mother's education in a population of individuals with different characteristics (i.e. unconditional effects) rather than in the impact for sub-groups with specific values of covariates (i.e. conditional effects). Unconditional recentred influence function quantile regression developed by Firpo et al. to assess the unconditional quantile effects of changes in covariates was employed in the present study [34]. The method consists of employing a regression of a transformation - the recentered influence function (RIF) - of the dependent variable (Y) on the explanatory variables (X). Advantage of this method is that it allows estimating the contribution of each explanatory variable for the components of the HAZ decomposition and thus extends the Blinder and Oaxaca decomposition to other distributional statistics than the mean [35]. The rationale behind application of such quantile regression based counterfactual decomposition (QR-CD) approach would be strengthened if there are important differences across the HAZ distribution in the relative contributions of covariate and coefficient effects to period-wise changes.

To estimate the unconditional quantile regression, first we have derived the RIF of the response variable (HAZ score, in our case). The RIF for the $\mathbb{B}_{\text {th }}$ quantile is given by the following expression: 
$\operatorname{RIF}\left(Y, q_{\tau}\right)=q_{\tau}+\frac{\tau-I\left(Y \leqslant q_{\tau}\right)}{f_{y\left(q_{\tau}\right)}}$

Where $f_{Y(q \mathbb{Q})}$ is the marginal density function of $\mathrm{Y}$ at the point $q_{\mathbb{Z}}$ estimated by kernel methods; $\mathrm{q}_{\mathbb{B}}$ is the sample quantile; $\mathrm{I}\left(\mathrm{Y} \leq \mathrm{q}_{\mathbb{Z}}\right)$ is an indicator function indicating whether the value of the outcome variable is below $q_{\mathbb{Z}}$. RIF provides a linear approximation to a non-linear functional $(v(Y))$ (such as median) of the $Y$ distribution and thus allow computing partial effects for single covariates [34]. Firpo et al. have also shown that by estimating OLS of the new dependent transformed variable on the covariates $(X)$, the RIF quantile regression may be implemented [34]. In case of this study, considering two periods $\left(t_{1}\right.$ and $\left.t_{2}\right)$, RIF regressions for HAZ score in both periods are estimated as:

$E\left[R I F\left(Y_{i e g} ; q_{\tau}\right) \mid X_{i e g}\right]=X_{i, g} \beta_{\tau, g} g=t_{1}, t_{2}(2)$

Coefficients $\beta_{\tau, g}$ represents the approximate marginal effects of the predictor variables on the HAZ quantile $q_{\tau}$ for children age 0-35 months in periods $g=t_{1}, t_{2}$.

Once we estimate the parameter $\beta_{\tau, \mathrm{g}}$ for each year in the sample, Oaxaca-Blinder decomposition was applied using RIF unconditional quantile estimates for any given quantile by following equation-

$$
\widehat{q_{\tau}}\left(H A Z_{t_{-} 2}\right)-\widehat{q_{\tau}}\left(H A Z_{t_{-} 1}\right)=\left[\overline{X_{t_{-} 2}}\left(\widehat{\beta_{C}}-\widehat{\beta_{t_{-} 2}}\right)+\widehat{R^{C o \bar{e} f}}\right]+\left[\left(\overline{X_{t_{-} 1}} \widehat{\beta_{t_{-} 1}}-\overline{X_{t_{-} 2 .}} \widehat{\beta_{C}}\right)+\widehat{R^{\operatorname{Cov}}}\right]
$$

Where $t_{2}$ is the final year and $t_{1}$ is the initial year. In our application, we set up the initial years as 1992-93, 1998-99, and 2005-06 and the final years as 1998-99, 2005-06, and 201516 respectively. As typical in Oaxaca-Blinder decomposition, the term $\widehat{q_{\tau}}\left(H A Z_{t_{-} 2}\right)-$ $\widehat{q_{\tau}}\left(H A Z_{t_{-1}}\right)$ represents the raw differences in $t_{2}$ and $t_{1} \mathrm{HAZ}$ scores at the $\tau^{\text {th }}$ quantile and $\mathrm{X}$ represents the covariate averages. The term $\overline{X_{t_{-}}}\left(\widehat{\beta_{C}}-\widehat{\beta_{R}}\right)$ refers to the coefficient effect and $\left(\overline{X_{t_{-}} 1} \widehat{\beta_{t_{-} 1}}-\overline{X_{t_{-} 2}} \widehat{\beta_{C}}\right)$ represents the differences between $t_{2}$ and $t_{1}$ scores attributable to the differences in characteristics of endowments and hence represents the covariate effect. $\widehat{R} \widetilde{C o e f f}$ and $\widetilde{R} \widetilde{C o v}$ are errors related to the estimation of coefficient and covariate effects.

Although the current research started with reduced form of conceptual framework of UNICEF [46], a further refinement of covariate set was required since decomposition of observed HAZ differences into covariate and coefficient effects require well-specified regressions models which should include key relevant covariates [30]. The final regression models include following covariates representing child, maternal, household and spatial characteristics as mentioned in the preceding section.

To note, we have tried our best to minimize endogeneity problems, and is consistent with previous literature [29-30], though endogeneity could persist and can lead to difficulties in parameter interpretation. However, as O'Donnell et al. noted that objective of the counterfactual decomposition is not solely causal identification, but to explain variations in child's HAZ and decide the relative values of covariate and coefficient effects [36]. One should cautiously interpret the coefficients of variables that are potentially endogenous; however, the decomposition itself remains valid.

\section{Results}

\section{Descriptive statistics}

Table 2 reveals percentile of HAZ scores adjusted by kernel smoothing for the four rounds of NFHS. HAZ scores of first and second rounds of NFHS are not strictly comparable because of territorial changes as mentioned earlier. The HAZ values of Bihar were also compared with the HAZ values of overall India. Without loss of generality, one can note that absolute increase in overall HAZ scores was the highest between second and third rounds of NFHS (i.e. between 1998-99 and 2005-06) followed by third and fourth rounds i.e. between 2005-06 and 2015-16. Child's HAZ scores largely remained at the same level between 1992-93 and 1998-99. Absolute increase of child's HAZ scores was remarkable for the bottom quantiles between 1998-99 
and 2005-06 nationally and in Bihar, in particular. In Bihar, there was even decline of HAZ scores at the top quantile. However, between 2005-06 and 2015-16, absolute increase in the HAZ scores was observed at the top quantile nationally as well as in Bihar. In other words, nutritionally better-off children gained more compared to the severely stunted during last decade.

Table 3 depicts socio-demographic and economic characteristics of the samples in four rounds of NFHS. It has been observed that initiation of early breastfeeding (within one hour of birth) has improved dramatically - more than 14-times - between 2005-06 and 2015-16. Although number of siblings of the index child has been declined in the recent past, it still indicates fertility in the state is high. Notably, benefit received from ICDS services increased by more than 7-fold between 2005-06 and 2015-16. Similar is the case for institutional delivery of mothers. Mother's age at first child has increased by nearly two years during the study period. BMI of mothers has improved between 2005-06 and 2015-16, while rate of decline of anaemia was substantial between 1998-99 and 2005-06 compared to 2005-06 and 2015-16. Mother's educational level has improved marginally in all the rounds. Although workforce participation rate among mothers remained consistent around 20 percent during 1992-93 and 2005-06, it has declined by half between 2005-06 and 2015-16. Degree of media exposure was found to have increased marginally over the years.

Majority of the respondents in the sample was Hindu and non-SC/ST, including OBCs. It is surprising to find out that proportion of economically marginalized households in the sample has increased from 1998-99, in spite of the state's higher economic growth during these periods, particularly after 2005 [37]. Being the least urbanised state of the country (among the major states), overwhelming proportion of the sample belong to the rural areas of Bihar.

\section{Unconditional RIF quantile regression results}

The estimates derived from unconditional RIF quantile regressions (QR) separately for all the survey periods were shown in Tables 4 and 5 . It has been observed that child age has negative and significant influence with child's HAZ scores across quantiles. If one moves from the lower tail to the upper tail, this effect increases, indicating that children starting with better nutritional status stand to lose more through faltering as they grow older. Although such observation holds for second and third rounds of survey, said observation confirms up to 75 percent quantile for first and fourth rounds. Girls were found to have significantly better HAZ outcomes compared to boys across quantiles; however, strength of association varies across quantile and period of survey. Child's size at birth (proxy for birth weight) was found to have varying association with HAZ scores across quintiles during first two rounds, in third and fourth rounds, size of the birth of children did not have any significant effect on HAZ scores. Early initiation of breastfeeding found to have positive and significant effect on HAZ scores in first round, while such effect weakened during the last three rounds. Higher sibling size has negative significant influence on child's HAZ scores, particularly those belong to the lower quantiles in third and fourth rounds of survey. Receipt of any benefit from ICDS found to be negatively associated with child's HAZ scores and such effect increases when we go from lower tail to higher tail of the HAZ distribution in the last round of survey.

Institutional delivery of mother, which is an important indicator for contact with health personnel, has positive and significant influence on child's HAZ scores across quantiles, particularly at the lower and middle quantile in varying degree except during the third round of the survey. Significant positive effect of higher age of mother's first birth on child's HAZ outcomes was found in the higher quantiles during the first and the latest rounds of survey, but not in other rounds. Notably, significant positive influence of maternal education on child's HAZ scores decreased with rounds.

Working mothers are significantly more likely to have children with lower HAZ scores compared to their non-working counterparts across quantiles during first round of the survey; however, such association holds only in lower quantiles in second and fourth rounds. Mother's exposure to any mass media found to have positive significant influence in the middle and upper quantiles of HAZ scores in the first round, though weakened in other rounds. Maternal height and BMI both have small but significant influence in enhancing child's HAZ scores across quantiles, such association strengthen in the last two rounds of survey. Degree of maternal empowerment found to have positive significant effect on child's HAZ scores during second round of the survey; however, such relationship weakened during last two rounds.

Differentials with respect to religion and caste affiliation were found in child's HAZ scores during first round of the survey; however, the relationship weakened thereafter. Significant positive influence of household affluence on child's HAZ outcomes was found during first and third round of survey and observation suggests the effect is higher among those belonging to higher quantiles. The results also revealed that rural-urban differentials in child's HAZ outcomes diminished over the period in Bihar.

\section{Quartile regression Oaxaca Blinder counterfactual decomposition (QR-CD)}

The estimated QR-CD results at the aggregate level of child, maternal, household and spatial characteristics were presented in the Tables 6-8, while a detailed breakdown of contribution of these characteristics were given in the Appendix Tables A1-A3.

Before interpreting the results, it should be kept in mind that the negative sign of the observed raw gap in HAZ scores between two successive periods reflects the fact that raw HAZ scores of the later period was lower than the previous period in all quantiles, except at the highest quantile between second and third rounds. Additionally, it must also be kept in mind that the direction of effect of contribution of characteristics as shown in the Tables 6-8 - negative figures imply a contribution to increase in the disparity in HAZ scores over time, while positive figures show a contribution to diminish it. A careful look to these tables reveals certain pattern of covariate effects and coefficient effects across quantiles and over the periods. 
It may be observed that between the periods 1992-93 and 1998-99 covariate (or endowments) effects contributed significantly to enhance disparities in child HAZ outcomes, at the $10^{\text {th }}, 50^{\text {th }}$ and $75^{\text {th }}$ quantiles, while coefficient (returns to endowments) effects dominates over covariate effect in enhancing disparities in child's HAZ outcomes at $90^{\text {th }}$ quantile (see Table 6). Lower panel of the Table 6 suggests that child endowments alone contributed 36.5 percent at $90^{\text {th }}$ quantile to 270.8 percent at $25^{\text {th }}$ quantile in explaining disparities in child's HAZ outcomes. Effect of mother's characteristics (or mother's endowments) in explaining such disparities was found to be relatively small and varies between -8.8 percent at $90^{\text {th }}$ quantile to 38.4 percent at $25^{\text {th }}$ quantile, while effects of household characteristics have tried to reduce covariate effects, particularly in $10^{\text {th }}$ and $25^{\text {th }}$ quantiles.

Notwithstanding, the directions of covariate and coefficient effects reversed significantly between the periods 1998-99 and 2005-06 as well as between 2005-06 and 2015-16 (see Tables 7 and 8). During both the periods, coefficient effects (or returns to endowments) significantly surpassed covariate effects (or endowments) in most of quantiles except the bottom quantile. Between 1998-99 and 2005-06, coefficient effects enhanced disparities in child's HAZ outcomes by $89-254.5$ percent between $25^{\text {th }}$ and $75^{\text {th }}$ quantiles (see Table 7 ), while such effects vary between $117-168.7$ percent between the same quantile (see Table 8). Additionally, between the said periods, coefficient effects enhanced disparity in child's HAZ outcomes even at the $90^{\text {th }}$ quantile. The lower panels of the Tables 7 and 8 revealed that between 1998-99 and 2005-06, coefficient effects of child characteristics significantly increased disparities across quantiles, while said effects of mother's characteristics have tried to reduce it except at $25^{\text {th }}$ and $50^{\text {th }}$ quantiles. Further, coefficient effects of the household attributes have tried to increase disparities in HAZ outcomes significantly at $25^{\text {th }}$ and $75^{\text {th }}$ quantiles between 1998-99 and 2005-06 and $10^{\text {th }}$ to 50 th quantiles between 2005-06 and 2015-16. Additionally, during the last period, positive and significant covariate effects were observed at the higher tails of HAZ distribution.

If covariate effects and coefficient effects of different attributes are looked in more disaggregated manner during the study period (as given in the Appendix A1-A3), it has been found that these effects vary across quantiles, periods and nature of endowment. For example, delivery in institutions was found to have significant effect in enhancing disparities, particularly between lower tails of the HAZ distribution between 1992-93 and 1998-99 (Appendix Table A1), coefficient effects of mother's height and BMI, and, media exposure have tried to reduce disparities across quantiles between 1998-99 and 2005-06 (Appendix Table A2). During the same period, covariate effect of institutional delivery has contributed significantly in increasing disparities. Between 2005-06 and 2015-16, both covariate and coefficient effects of the receipt of ICDS services were found to be significantly associated with reduction of HAZ disparities among children (Appendix Table A3).

\section{Discussion}

The QR-CD method provides specific insight into the drivers of disparities across child's HAZ distribution. The understanding of factors resulted in disparities in the lower quantiles of HAZ scores would be useful in designing interventions aimed at the vulnerable households with children of the highest levels of stunting. In order to assess the contribution of the 'returns' to various interventions in reducing child HAZ disparities during last two decades, such quantification of the contribution of different socio-demographic, economic and cultural determinants seemed to be imperative for the state of Bihar.

This study indicates that although between 1992-93 and 1998-99 child's HAZ disparity at the bottom quantile of the distribution was largely accounted for differing levels of endowments, in the later periods such differences weakened statistically. In other words, between 1992-93 and 1998-99, at the lowest quantile, reducing disparity in childhood stunting was a matter of equalizing endowments; however, between 1998-99 and 2015-16, both unequal endowments as well as dissimilar access to the benefits of implementation of government sponsored schemes - were largely responsible for childhood HAZ disparity. At the higher quantiles, particularly between $50-75^{\text {th }}$ quantile, although unequal endowments were responsible for such disparities between 1992-93 and 1998-99, inadequate access to benefits from programme implementation was largely found accountable between 1998-99 and 2005-06 as well as between 2005-06 and 2015-16.

From the QR-CD estimates between 2005-06 and 2015-16, it is important to note that there are limited number of equalizing endowments which can have significant influence in reducing disparities in child HAZ outcomes for the bottom quintiles, though at the aggregate level influences of endowments were statistically weak. According to the current estimates, much of the reduction of disparities at the lowest quantile can be achieved by maintaining regularity of ICDS services, early initiation of breastfeeding, reduction in sibling size (proxy for fertility size), increasing mother's age at first birth, mass media exposure, educational attainment and employability. Additionally, access to the programmes pertaining to initiation of early breastfeeding, securing access and reducing gender-gap in receipt of ICDS services, reduction of early childbearing, improving mother's nutritional status, and creation of household wealth found to be imperative to the households having the highest level of stunting. Because coefficient effects indicate all-inclusive returns to endowments, arguably, not only the 'reach' of these programmes, but also ensuring 'quality of these programmes also could enhance child nutritional status. Although earlier studies have also demonstrated the influence of these characteristics to lowering stunting [3839], these studies could not able to quantify the contribution of reach of various policies and programmes in reducing stunting.

In addition to the implementation of centrally sponsored schemes such as ICDS, the government of Bihar has initiated a number of programmes in the recent past which have indirect influence in the reduction of child undernutrition. Currently 18 centrally sponsored schemes and 30 state-specific nutrition-sensitive schemes are being implemented by 16 departments. It would have been more meaningful and easier to monitor if all these schemes can be brought under a single umbrella of a State Nutrition Mission. How a State's Nutrition Mission can successfully reduce the menace of child 
undernutrition has been well-documented for the state of Maharashtra in India [40]. The key factors identified in the policy processes in the success of Maharashtra include the way the issue was framed and available evidences helped catalyse a political response; forming State Nutrition Mission as response from government structures, and system-wide capacity was combined with leadership in an innovative fashion in utilizing available resources.

Nonetheless, the Draft State Plan of Action for Children 2017 proposed 11 strategies and actions for all-round development for children. These include effective implementation of schemes, programmes and laws; mapping vulnerable households and linking those households with appropriate development schemes; raising community awareness on the nutritional issues through institutional interventions; institutional strengthening through capacity building of staff, improved infrastructure and outreach; strengthening child-relevant resources and facilitating uptake of principal schemes and services etc. The state plans for action also emphasized 'breaking the intergenerational cycle of malnutrition' by provisioning take-home ration and ensuring safe health and hygiene practices through better outreach services, particularly in the lower performing districts. The said action plan must also accommodate the issue of intersectoral coordination in implementation of these programmes in order to harness better dividend of these schemes.

Some limitations of the study should be acknowledged. First, NFHS sampling frame of 1998-99 does not allow to separate districts from the states. However, because of unavailability of any other comparable dataset, it was compelling to segregate districts of undivided Bihar. This may under- or over-estimate the QR-CD results to a disproportionate extent. Secondly, CD exercise can provide reliable estimates only if the primary quantile regression includes all the important factors of child nutrition and is well-specified [29]. To note, the choice of determinants has been constrained by the coverage of NFHS, key variables considered by the previous literature were included in the present study [18, 29-30]. However, in such situation, the issue of endogeneity cannot be entirely ruled out, though necessary tests were carried out to get rid of this. Thirdly, providing clinical interpretations of the effect size of the variables are beyond the scope of the present study. Finally, the 'coefficient effects' in such comparisons lump several potential effects together and not informative about specific factors or actions [30]; thus, interpretations of coefficient effects are speculative. Nonetheless, this research helps to highlight important dimensions to child nutritional improvement during last two decades for the state of Bihar.

\section{Conclusion}

Inconspicuous presence of child nutrition in Millennium Development Goals (MDG) framework with an imperfect measure of child undernutrition (i.e. underweight) was criticised. However, the issue has gained considerable momentum in the Sustainable Development Goals (SDGs) as the ambition to 'end hunger, achieve food security and improved nutrition and promote sustainable agriculture' is captured in SDG 2 . Further, at least 12 of the 17 Goals contain indicators, which are highly relevant to nutrition because of the fact that without adequate and sustained investments in good nutrition, the SDGs would not be realised. Results of the present study suggest that child undernutrition in Bihar is not just from a lack of sufficient and adequately nutritious and safe food, but from a host of intertwined factors linking healthcare, women's education and work, household wealth (including water, sanitation and hygiene) and more. In addition to scaling-up proven nutrition-specific interventions in other Indian states, the state of Bihar, must focus on policy processes and their political underpinnings reduce the risk of child undernutrition.

\section{Abbreviations}

NFHS: National family health Survey

DHS: Demographic Health Survey

AOR: Adjusted Odds Ratio

RIF: Re-Centred Influence Function

HAZ: Height for age Z score

SDG: Sustainable Development Goals

IIPS: International Institute for Population Sciences

\section{Declarations}

\section{Ethics approval and consent to participate}

The study used fourth round of National Family Health Survey (NFHS) data, which is available publicly available. Before conducting the survey NFHS had taken ethical approval. For the present study, ethical approval is not required.

\section{Consent for publication}

Not applicable for this study. 
Availability of data and materials

The datasets generated and/or analysed during the current study are available in the [DHS] repository, [www.dhsprogram.com]

\section{Competing interests}

Authors do not have any competing interest.

\section{Funding}

This work was supported by the Bill \& Melinda Gates Foundation [OPP1164044]

\section{Authors' contributions}

SG and DB conceived the idea.

SG implemented the idea.

SKS analysed the data and prepared the tables.

SG prepared the draft.

DB commented on the draft and made necessary changes.

\section{Acknowledgements}

Authors sincerely acknowledge the colleagues at the Asian Development Research Institute for their suggestions and comments. Authors are also extend their heartiest thanks to the referees of the paper for their valuable and insightful comments.

\section{Authors' information (optional)}

Not required

Endnote 1: Women's empowerment indicators were created from factor scores of the factor analyses using different variables indicating women's household decision making power, freedom of movement etc. For NFHS 2, 1998-99, following variables were included: who decides how to spend money, who decides obtaining health care, who decides what to cook, permission need to go to market, and permission needed to visit relatives or friends. Women's work for cash in the past 12 months was also incorporated. In NFHS 3, 2005-06, final say on how to spend money, final say on own health care, final say on household purchases, final say on visit relatives or friends, Work for cash in the past 12 months, having bank account were considered to create such index. In NFHS 4, 2015-16, the variables such as who decides on own health care, who decides on how to spend money, who decides on household purchases, who decides on visit relatives or friends, owning house/land, Work for cash in the past 12 months, having bank account, and having mobile were included in the analysis.

\section{References}

1. International Institute for Population Sciences (IIPS) and ICF. 2017. National Family Health Survey (NFHS-4), 2015-16: India. Mumbai: IIPS.

2. Improving child nutrition: the achievable imperative for global progress. New York: UNICEF. 2013; 1-4.

3. Headey DD. Developmental drivers of nutritional change: a cross-country analysis. World Dev. 2013 Feb 1; $42: 76-88$.

4. Jose S, Reddy B, Agrawal M. Child Undernutrition in India: Assessment of Prevalence, Decline and Disparities. Econ. Political Wkly. 2018 ; 53:63-9.

5. Nayak BS, Unnikrishnan B, Ravishankar N, Shetty A, Mundkur SC. Malnutrition among Children in Karnataka: A Systematic Review and MetaAnalysis. J Clin \& Diagn Research. 2018; 12(11).

6. Sari M, De Pee S, Bloem MW, Sun K, Thorne-Lyman AL, Moench-Pfanner R, Akhter N, Kraemer K, Semba RD. Higher household expenditure on animal-source and nongrain foods lowers the risk of stunting among children $0-59$ months old in Indonesia: implications of rising food prices. $J$ Nutr. $2009 ; 140(1): 195 S-200 S$.

7. Humphries DL, Dearden KA, Crookston BT, Woldehanna T, Penny ME, Behrman JR. Household food group expenditure patterns are associated with child anthropometry at ages 5, 8 and 12 years in Ethiopia, India, Peru and Vietnam. Econ \& Hum Bio. 2017; 26:30-41.

8. Subramanyam MA, Kawachi I, Berkman LF, Subramanian SV. Is economic growth associated with reduction in child undernutrition in India? PLoS Med. 2011;8(3): e1000424.

9. Gwatkins DK, Rutstein S, Johnson K, Suliman E, Wagstaff A, Amouzou A. Socio-economic differences in health, nutrition, and population within developing countries. Washington, DC, World Bank; 2007.

10. Harttgen K, Klasen S, Vollmer S. Economic growth and child undernutrition in sub-Saharan Africa. Pop dev rev. 2013; $39(3): 397-412$.

11. Spears D. How much international variation in child height can sanitation explain? The World Bank; 2013.

Page $9 / 20$ 
12. https://openknowledge.worldbank.org/bitstream/handle/10986/13163/wps6351.pdf?sequence=1

13. Rah JH, Cronin AA, Badgaiyan B, Aguayo VM, Coates S, Ahmed S. Household sanitation and personal hygiene practices are associated with child stunting in rural India: a cross-sectional analysis of surveys. BMJ Open. 2015; 5(2): e005180.

14. Black RE, Victora CG, Walker SP, Bhutta ZA, Christian P, De Onis M, Ezzati M, Grantham-McGregor S, Katz J, Martorell R, Uauy R. Maternal and child undernutrition and overweight in low-income and middle-income countries. The lancet. 2013;382(9890):427-51.

15. Rachmi CN, Agho KE, Li M, Baur LA. Stunting, underweight and overweight in children aged 2.0-4.9 years in Indonesia: prevalence trends and associated risk factors. PloS One. 2016; 11(5): e0154756.

16. Géa-Horta T, Silva RD, Fiaccone RL, Barreto ML, Velásquez-Meléndez G. Factors associated with nutritional outcomes in the mother-child dyad: a population-based cross-sectional study. Public Health Nutr. 2016;19(15):2725-33.

17. Vollmer S, Bommer C, Krishna A, Harttgen K, Subramanian SV. The association of parental education with childhood undernutrition in low-and middle-income countries: comparing the role of paternal and maternal education. Int J Epid. 2016; 46 (1):312-23.

18. Imai KS, Annim SK, Kulkarni VS, Gaiha R. Women's empowerment and prevalence of stunted and underweight children in rural India. World Dev. 2014; 62:88-105.

19. Menon P, Headey D, Avula R, Nguyen PH. Understanding the geographical burden of stunting in India: A regression-decomposition analysis of district-level data from 2015-16. Mat Child Nutr. 2018; 14(4): e12620.

20. Khan J, Mohanty SK. Spatial heterogeneity and correlates of child malnutrition in districts of India. BMC Public Health. 2018; $18(1): 1027$.

21. Bajpai V. The challenges confronting public hospitals in India, their origins, and possible solutions. Adv Public Health. $2014 ; 2014$.

22. Barik D, Thorat A. Issues of unequal access to public health in India. Front Pub health. 2015; 3:245.

23. Sanneving L, Trygg N, Saxena D, Mavalankar D, Thomsen S. Inequity in India: the case of maternal and reproductive health. Glob Health Act. 2013; 6(1):19145.

24. Harriss J, Kohli N. Notes on the differing 'states' of child undernutrition in rural India. IDS Bulletin. 2009; 40(4):9-15.

25. Jain M. India's struggle against malnutrition-Is the ICDS program the answer? World Dev. 2015; 67:72-89.

26. Kandpal E. Beyond average treatment effects: distribution of child nutrition outcomes and program placement in India's ICDS. World Dev. 2011; 39(8):1410-21.

27. Singh N, Gupta P. Impact of ICDS services in urban and rural area beneficiaries' children of Ghaziabad, Uttar Pradesh, India: a comparative evaluation study. International Journal of Comm Med Pub Health. 2017; 3(1):287-92.

28. Mittal N, Meenakshi JV. Does the ICDS Improve Children's Diets? Some Evidence from Rural Bihar. J Dev Stud. 2018; 1-6.

29. Mukhopadhyay, S. (2013). Do public services reach the worst affected children in rural India? An investigation applying quantile regression method. Child Indicator Research, 6, 527-546.

30. Srinivasan CS, Zanello G, Shankar B. Rural-urban disparities in child nutrition in Bangladesh and Nepal. BMC Pub Health. 2013 ; $13(1): 581$.

31. Cavatorta E, Shankar B, Flores-Martinez A. Explaining cross-state disparities in child nutrition in rural India. World Dev. 2015; 76: 216-37.

32. ICMR P. Health of the Nation's States-The India State-Level Disease Burden Initiative. New Dehli: Indian Council of Medical Research. Public Health Foundation of India, Institute for Health Metrics and Evaluation. 2017.

33. Filmer D, Pritchett LH. Estimating Wealth Effects without Expenditure Data-or Tears: An Application to Educational enrolments in states of India. 2001; 38(1): 115-132.

34. Koenker R, Bassett Jr G. Regression quantiles. Econometrica: J Econ Soc. 1978 Jan 1:33-50.

35. Firpo S, Fortin NM, Lemieux T. Unconditional quantile regressions. Econometrica. 2009; 77(3):953-73.

36. Fortin N, Lemieux T, Firpo S. Decomposition methods in economics. In Handbook of labour economics. 2011; 4: 1-102. Elsevier.

37. O'Donnell O, Nicolás ÁL, Van Doorslaer E. Growing richer and taller: Explaining change in the distribution of child nutritional status during Vietnam's economic boom. J Dev Econ. 2009; 88(1):45-58.

38. Government of Bihar (GoB). Economic Survey 2015-16, Finance Department, Government of Bihar. 2016. http://finance.bih.nic.in/Reports/Economic-Survey-2016-EN.pdf

39. Dewey KG. Reducing stunting by improving maternal, infant and young child nutrition in regions such as South Asia: evidence, challenges and opportunities. Mat Child Nutr. 2016; 12:27-38.

40. McGovern ME, Krishna A, Aguayo VM, Subramanian SV. A review of the evidence linking child stunting to economic outcomes. Int J Epidem. 2017; 46(4):1171-91.

41. Nisbett N, Barnett I. Explaining the reduction in child undernutrition in the Indian state of Maharashtra between 2006 and 2012: An analysis of the policy processes. Food policy. 2017; 70:27-39.

42. Garrett JL, Ruel MT. Are determinants of rural and urban food security and nutritional status different? Some insights from Mozambique. World Dev. 1999; 27(11):1955-75.

43. 1995. National Family Health Survey (MCH and Family Planning), India 1992-93. Bombay: IIPS.

Page $10 / 20$ 
44. IIPS and Macro International. 2007. National Family Health Survey (NFHS-3), 2005-06: India: Volume I. Mumbai: IIPS.

45. IIPS and ORC Macro. 2000. National Family Health Survey (NFHS-2), 1998-99: India. Mumbai: IIPS.

46. WHO child growth standards: methods and development. Geneva: World Health Organization; 2006.

\section{Tables}

\begin{tabular}{|c|c|c|}
\hline Demographic and Health Indicators & 1992-93 & 2015-16 \\
\hline Sex ratio (female/1000 male) & $956^{\mathrm{a}}$ & $1062^{c}$ \\
\hline$\%$ population aged $6+$ that is literate & $44.6^{\mathrm{a}}$ & $66.9^{c}$ \\
\hline$\%$ female population aged $6+$ that is literate & $28.6^{\mathrm{a}}$ & $57.0^{\mathrm{c}}$ \\
\hline Child (0-6 years) sex ratio & $944^{\mathrm{a}}$ & $939^{c}$ \\
\hline Infant mortality rate & $89.2^{\mathrm{a}}$ & $48.2^{c}$ \\
\hline Total fertility rate & $3.25^{\mathrm{a}}$ & $3.40^{c}$ \\
\hline$\%$ mothers who had at least 3 ANC for last birth & $30.7^{a}$ & $14.4^{\mathrm{c}}$ \\
\hline$\%$ skilled attendance at delivery & $19.0^{\mathrm{a}}$ & $70.0^{c}$ \\
\hline$\%$ institutional delivery & $13.0^{\mathrm{a}}$ & $63.8^{c}$ \\
\hline Head count poverty ratio & $61 \%{ }^{b}$ & $34 \%{ }^{b}$ \\
\hline Singulate Mean age at marriage & $18.0^{\mathrm{a}}$ & $19.5^{d}$ \\
\hline
\end{tabular}

Sources: aNFHS 1 (1992-93); ${ }^{b}$ World Bank 2016; c NFHS 4 (2015-16); dIIPS 2016

\begin{tabular}{|c|c|c|c|c|c|c|c|}
\hline Bihar & $\underset{1}{\text { NFHS }}$ & ${ }_{2}^{N F H S}$ & $\underset{3}{\text { NFHS }}$ & $\underset{4}{N F H S}$ & $\begin{array}{l}\text { Absolute increase btw NFHS } 1 \\
\text { and NFHS } 2\end{array}$ & $\begin{array}{l}\text { Absolute increase btw NFHS } 2 \\
\text { and NFHS } 3\end{array}$ & $\begin{array}{l}\text { Absolute increase btw NFHS } 3 \\
\text { and NFHS } 4\end{array}$ \\
\hline 10 & -4.92 & -4.89 & -4.03 & -3.74 & 0.03 & 0.86 & 0.29 \\
\hline 25 & -3.85 & -3.75 & -2.95 & -2.81 & 0.10 & 0.80 & 0.14 \\
\hline 50 & -2.49 & -2.46 & -1.93 & -1.80 & 0.03 & 0.54 & 0.13 \\
\hline 75 & -1.09 & -1.08 & -0.84 & -0.61 & 0.01 & 0.24 & 0.23 \\
\hline 90 & 0.12 & 0.36 & 0.19 & 0.65 & 0.24 & -0.17 & 0.46 \\
\hline Overall & -2.36 & -2.28 & -1.89 & -1.63 & 0.07 & 0.40 & 0.26 \\
\hline India & $\underset{1}{\text { NFHS }}$ & $\begin{array}{l}\text { NFHS } \\
2\end{array}$ & $\begin{array}{l}\text { NFHS } \\
3\end{array}$ & $\begin{array}{l}\text { NFHS } \\
4\end{array}$ & $\begin{array}{l}\text { Absolute increase btw NFHS } 1 \\
\text { and NFHS } 2\end{array}$ & $\begin{array}{l}\text { Absolute increase btw NFHS } 2 \\
\text { and NFHS } 3\end{array}$ & $\begin{array}{l}\text { Absolute increase btw NFHS } 3 \\
\text { and NFHS } 4\end{array}$ \\
\hline 10 & -4.26 & -4.19 & -3.72 & -3.49 & 0.07 & 0.47 & 0.24 \\
\hline 25 & -3.16 & -3.10 & -2.70 & -2.48 & 0.06 & 0.40 & 0.22 \\
\hline 50 & -2.00 & -1.96 & -1.63 & -1.43 & 0.04 & 0.33 & 0.20 \\
\hline 75 & -0.85 & -0.82 & -0.51 & -0.27 & 0.03 & 0.31 & 0.24 \\
\hline 90 & 0.32 & 0.31 & 0.64 & 0.99 & -0.01 & 0.33 & 0.35 \\
\hline Overall & -1.94 & -1.91 & -1.55 & -1.30 & 0.03 & 0.36 & 0.25 \\
\hline
\end{tabular}




\begin{tabular}{|c|c|c|c|c|c|c|c|c|}
\hline & NFHS 1 & $\mathbf{N}$ & NFHS 2 & $\mathbf{N}$ & NFHS 3 & $\mathbf{N}$ & NFHS 4 & $\mathbf{N}$ \\
\hline Child HAZ [mean (SD)] & $-2.36(0.05)$ & 1821 & $-2.29(0.05)$ & 1627 & $-1.89(0.05)$ & 1188 & $-1.63(0.04)$ & 2184 \\
\hline Age of Child in Month[mean(SD)] & $16.3(9.6)$ & 1821 & 16.4(10.6) & 1627 & 17.5(10.1) & 1188 & 17.7(10.1) & 2184 \\
\hline Age2 [mean(SD)] & $357.2(342.7)$ & 1821 & $378.5(376.0)$ & 1627 & $405.5(367)$ & 1188 & $414.7(373.7)$ & 2184 \\
\hline Male & 49.5 & 902 & 52.1 & 847 & 53.5 & 635 & 51.8 & 1131 \\
\hline Female & 50.5 & 919 & 47.9 & 779 & 46.6 & 553 & 48.2 & 1053 \\
\hline \multicolumn{9}{|l|}{ Birth Size } \\
\hline Normal & 71.9 & 1309 & 69.5 & 1130 & 47.2 & 561 & 69.34 & 1514 \\
\hline \multicolumn{9}{|l|}{ Early Breastfeeding } \\
\hline No & 98.2 & 1766 & 95.6 & 1406 & 97.4 & 1146 & 63.4 & 1151 \\
\hline Yes & 1.8 & 30 & 4.4 & 65 & 2.6 & 31 & 36.6 & 665 \\
\hline No. of Sibling [mean(SD)] & $1.88(1.7)$ & 1821 & $1.96(1.8)$ & 1627 & $2.06(1.9)$ & 1188 & $1.62(1.4)$ & 2184 \\
\hline \multicolumn{9}{|l|}{ Benefitted ICDS services } \\
\hline No & - & & - & & 92.1 & 1094 & 39.0 & 853 \\
\hline Yes & - & & - & & 7.9 & 94 & 61.0 & 1331 \\
\hline \multicolumn{9}{|l|}{ Mother's Characteristics } \\
\hline BMI of mother [mean(SD)] & - & & $19.34(2.5)$ & 1627 & $19.30(2.6)$ & 1188 & $20.06(3.2)$ & 2184 \\
\hline \multicolumn{9}{|l|}{ Mother's anaemia } \\
\hline No & - & & 71.1 & 1156 & 73.1 & 849 & 65.84 & 1438 \\
\hline Yes & - & & 28.9 & 470 & 26.9 & 313 & 34.16 & 746 \\
\hline Mother's height in cm [mean(SD)] & - & & $149.6(5.4)$ & 1627 & $150.0(5.4)$ & 1188 & $149.5(5.8)$ & 2184 \\
\hline Mother's Education (mean) & $2.02(4.0)$ & 1821 & $2.01(3.8)$ & 1627 & $2.93(4.5)$ & 1188 & $3.98(4.9)$ & 2184 \\
\hline \multicolumn{9}{|l|}{ Working mother } \\
\hline No & 78.1 & 1422 & 80.6 & 1306 & 79.9 & 950 & 89.2 & 1964 \\
\hline Yes & 21.9 & 399 & 19.7 & 321 & 20.1 & 238 & 10.2 & 220 \\
\hline Media exposure & $0.47(0-3)$ & 1821 & $0.43(0-3)$ & 1627 & $0.60(0-3)$ & 1627 & $1.31(0-3)$ & 2184 \\
\hline \multicolumn{9}{|l|}{ Religion } \\
\hline Hindu & 78.2 & 1424 & 82.4 & 1340 & 81.6 & 969 & 79.2 & 1731 \\
\hline Muslim/Others & 21.8 & 397 & 17.6 & 287 & 18.4 & 219 & 20.8 & 453 \\
\hline \multicolumn{9}{|l|}{ Caste } \\
\hline SC & 9.3 & 169 & 23.7 & 386 & 19.6 & 233 & 19.9 & 433 \\
\hline
\end{tabular}




\begin{tabular}{|c|c|c|c|c|c|c|c|c|}
\hline Poorest & 20.5 & 373 & 18.2 & 369 & 31.7 & 376 & 55.5 & 1217 \\
\hline Middle & 16.9 & 308 & 23.3 & 472 & 16.6 & 197 & 11.6 & 251 \\
\hline Richer & 13.8 & 252 & 23.2 & 471 & 12.5 & 149 & 6.3 & 137 \\
\hline Richest & 22.9 & 417 & 14.9 & 303 & 5.8 & 69 & 1.8 & 39 \\
\hline Urban & 13.1 & 238 & 6.2 & 101 & 11.1 & 132 & 10.8 & 236 \\
\hline Rural & 86.9 & 1583 & 93.8 & 1526 & 88.9 & 1056 & 89.2 & 1948 \\
\hline Total & 100.0 & 1821 & 100.0 & 1627 & 100.0 & 1188 & 100.0 & 2184 \\
\hline
\end{tabular}

Source: Computed by the authors from unit-level data of NFHS rounds; SD: standard deviation 


\begin{tabular}{|c|c|c|c|c|c|c|c|c|c|c|}
\hline & NFHS 1 & & & & & NFHS 2 & & & & \\
\hline & 10 & 25 & 50 & 75 & 90 & 10 & 25 & 50 & 75 & 90 \\
\hline \multirow[t]{2}{*}{ Age of Child } & $-0.073^{\star \star \star}$ & $-0.103^{\star \star \star}$ & $-0.171^{\star \star \star}$ & $-0.173^{\star \star \star}$ & $-0.086^{\star \star \star}$ & 0.025 & $-0.104^{\star}$ & $-0.237 * \star \star$ & $-0.303^{\star \star *}$ & $-0.419 * \star$ \\
\hline & $(0.006)$ & $(0.0078)$ & $(0.006)$ & $(0.007)$ & $(0.012)$ & $(0.062)$ & $(0.055)$ & $(0.060)$ & $(0.085)$ & $(0.195)$ \\
\hline \multirow[t]{2}{*}{ Age2 } & $0.001 * \star \star$ & $0.001^{\star \star \star}$ & $0.003^{\star \star \star}$ & $0.003^{\star \star \star}$ & $0.001^{\star \star \star}$ & -0.003 & 0.000 & $0.004^{\star \star}$ & 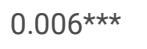 & $0.010 *$ \\
\hline & $(0.0002)$ & $(0.0002)$ & $(0.0002)$ & $(0.0002)$ & $(0.0003)$ & $(0.002)$ & $(0.002)$ & $(0.002)$ & $(0.002)$ & $(0.005)$ \\
\hline \multirow[t]{2}{*}{ Female } & 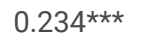 & $0.306 * \star \star$ & 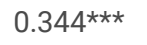 & 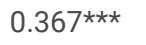 & $0.578 * \star \star$ & 0.442 & $0.625^{\star \star}$ & $1.089 * \star \star$ & 0.412 & 0.480 \\
\hline & $(0.035)$ & $(0.040)$ & $(0.032)$ & $(0.034)$ & $(0.054)$ & $(0.289)$ & $(0.305)$ & $(0.348)$ & $(0.422)$ & $(0.842)$ \\
\hline \multicolumn{11}{|l|}{ Birth Size } \\
\hline \multicolumn{11}{|l|}{ Normal } \\
\hline \multirow{2}{*}{$\begin{array}{l}\text { Average and } \\
\text { above }\end{array}$} & 0.054 & -0.102 & 0.077 & $0.485^{\star \star \star}$ & $0.332^{\star \star \star}$ & 0.218 & 0.580 & $0.833^{\star}$ & 0.944 & 2.332 \\
\hline & $(0.054)$ & $(0.065)$ & $(0.050)$ & $(0.060)$ & $(0.095)$ & $(0.404)$ & $(0.500)$ & $(0.451)$ & $(0.652)$ & $(1.472)$ \\
\hline \multirow[t]{2}{*}{ Small } & $-0.185^{\star \star \star}$ & -0.003 & 0.066 & 0.002 & 0.088 & -0.505 & 0.416 & 0.476 & $1.127^{\star}$ & -0.291 \\
\hline & $(0.049)$ & $(0.054)$ & $(0.044)$ & $(0.047)$ & $0.074)$ & $(0.518)$ & $(0.404)$ & $(0.465)$ & $(0.642)$ & $(1.111)$ \\
\hline \multirow{2}{*}{$\begin{array}{l}\text { Early } \\
\text { Breastfeeding } \\
\text { (Yes) }\end{array}$} & $0.820 * \star \star$ & $1.063^{\star \star \star}$ & $0.447 \star \star \star$ & $0.422^{\star \star \star}$ & -0.242 & -1.281 & -1.137 & -0.117 & -0.064 & $-2.467 * \star$ \\
\hline & $(0.035)$ & $(0.095)$ & $(0.127)$ & $(0.142)$ & $(0.192)$ & $(0.927)$ & $(0.787)$ & $(0.783)$ & $(1.228)$ & $(1.091)$ \\
\hline \multirow[t]{2}{*}{ No. of Sibling } & -0.003 & 0.007 & $-0.017 *$ & -0.013 & $0.036^{* *}$ & -0.089 & -0.014 & 0.109 & 0.146 & 0.158 \\
\hline & $(0.010)$ & $(0.012)$ & $(0.009)$ & $(0.010)$ & $(0.016)$ & $(0.126)$ & $(0.095)$ & $(0.100)$ & $(0.116)$ & $(0.211)$ \\
\hline \multicolumn{11}{|l|}{$\begin{array}{l}\text { Mother's } \\
\text { Characteristics }\end{array}$} \\
\hline \multirow{2}{*}{$\begin{array}{l}\text { Institutional } \\
\text { Delivery (yes) }\end{array}$} & $0.398 * \star \star$ & $0.888^{\star \star \star}$ & $0.398 * * \star$ & $0.135^{\star \star}$ & $-0.192 \star \star$ & 0.472 & 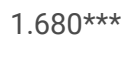 & $2.231^{\star \star}$ & 1.943 & 4.823 \\
\hline & $(0.054)$ & $(0.066)$ & $(0.061)$ & $(0.065)$ & $(0.094)$ & $(0.579)$ & $(0.611)$ & $(0.956)$ & (1.298) & $(3.050)$ \\
\hline \multirow{2}{*}{$\begin{array}{l}\text { Age of mother } \\
\text { at first birth }\end{array}$} & $-0.021 * \star \star *$ & 0.005 & -0.004 & $0.020 * \star \star$ & $0.051^{\star \star \star}$ & 0.061 & 0.018 & 0.045 & 0.000 & -0.006 \\
\hline & $(0.005)$ & $(0.007)$ & $(0.006)$ & $(0.007)$ & $(0.011)$ & $(0.063)$ & $(0.063)$ & $(0.063)$ & $(0.072)$ & $(0.159)$ \\
\hline \multirow[t]{2}{*}{ BMI of mother } & & & & & & 0.000 & 0.000 & $0.001^{\star \star \star}$ & 0.001 & 0.003 \\
\hline & & & & & & $(0.0004)$ & $(0.0004)$ & $(0.0003)$ & $(0.0008)$ & $(0.002)$ \\
\hline \multicolumn{11}{|l|}{$\begin{array}{l}\text { Mother's } \\
\text { anaemia }\end{array}$} \\
\hline \multirow[t]{2}{*}{ Yes } & - & - & - & - & - & 0.258 & -0.274 & $-0.998 * \star \star$ & 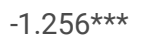 & $-2.049 \star *$ \\
\hline & & & & & & $(0.368)$ & $(0.373)$ & $(0.384)$ & $(0.469)$ & $(0.903)$ \\
\hline \multirow{2}{*}{$\begin{array}{l}\text { Mother's } \\
\text { height }\end{array}$} & & & & & & $0.006^{\star *}$ & 0.003 & $0.005^{\star}$ & $0.006^{*}$ & -0.003 \\
\hline & & & & & & $(0.003)$ & $(0.003)$ & $(0.003)$ & $(0.004)$ & $(0.008)$ \\
\hline \multirow{2}{*}{$\begin{array}{l}\text { Mother's } \\
\text { Education }\end{array}$} & 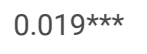 & 0.003 & $0.025^{\star \star \star}$ & $0.030 * \star \star$ & $0.025^{\star \star}$ & -0.003 & -0.047 & -0.100 & $-0.187 \star \star$ & -0.213 \\
\hline & $(0.005)$ & $(0.007)$ & $(0.006)$ & $(0.007)$ & $(0.010)$ & $(0.084)$ & $(0.097)$ & $(0.089)$ & $(0.075)$ & $(0.201)$ \\
\hline \multirow{2}{*}{$\begin{array}{l}\text { Working } \\
\text { mother }\end{array}$} & $-0.228^{\star \star \star}$ & $-0.551 * \star \star *$ & $-0.371^{* * *}$ & $-0.240 * \star \star$ & $-0.357 * * *$ & $-1.16^{\star \star}$ & $-1.52^{\star \star \star}$ & -0.868 & -0.331 & 0.354 \\
\hline & $(0.048)$ & $(0.054)$ & $(0.040)$ & $(0.041)$ & $(0.062)$ & $(0.568)$ & $(0.553)$ & $(1.089)$ & $(1.132)$ & (3.189) \\
\hline \multirow[t]{2}{*}{ Empowerment } & & & & & & -0.096 & 0.019 & $-0.252^{\star \star}$ & -0.193 & -0.316 \\
\hline & & & & & & $(0.141)$ & $(0.128)$ & $(0.103)$ & $(0.129)$ & $(0.239)$ \\
\hline \multirow{2}{*}{$\begin{array}{l}\text { Media } \\
\text { exposure }\end{array}$} & -0.016 & 0.011 & $0.157^{\star \star \star}$ & $0.172^{\star \star \star}$ & $0.241^{\star \star \star}$ & 0.020 & -0.247 & -0.341 & -0.394 & $-1.629 *$ \\
\hline & $(0.030)$ & $(0.033)$ & $(0.028)$ & $(0.034)$ & $(0.053)$ & $(0.281)$ & $(0.484)$ & $(0.440)$ & $(0.458)$ & $(0.927)$ \\
\hline \multicolumn{11}{|l|}{ Religion } \\
\hline Hindu & & & & & & & & & & \\
\hline
\end{tabular}




\begin{tabular}{|c|c|c|c|c|c|c|c|c|c|c|}
\hline Muslim/Others & $\begin{array}{l}-0.115^{\star \star \star} \\
(0.045)\end{array}$ & $\begin{array}{l}-0.141^{\star \star \star} \\
(0.052)\end{array}$ & $\begin{array}{l}-0.073^{*} \\
(0.042)\end{array}$ & $\begin{array}{l}-0.115^{\star \star \star} \\
(0.043)\end{array}$ & $\begin{array}{l}0.075 \\
(0.068)\end{array}$ & $\begin{array}{l}-0.468 \\
(0.585)\end{array}$ & $\begin{array}{l}0.481 \\
(0.501)\end{array}$ & $\begin{array}{l}0.912 \\
(0.619)\end{array}$ & $\begin{array}{l}0.802 \\
(0.765)\end{array}$ & $\begin{array}{l}2.375 \\
(1.774)\end{array}$ \\
\hline \multicolumn{11}{|l|}{ Caste } \\
\hline \multicolumn{11}{|l|}{ SC } \\
\hline \multirow[t]{2}{*}{ ST } & 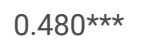 & $1.018^{\star \star \star}$ & $0.360 * \star \star$ & $0.179 * \star$ & $-0.435^{\star \star \star}$ & 0.126 & -1.027 & -0.097 & 0.325 & 0.369 \\
\hline & $(0.085)$ & $(0.098)$ & $(0.077)$ & $(0.082)$ & $(0.138)$ & $(1.215)$ & $(0.831)$ & $(0.830)$ & $(1.132)$ & $(2.086)$ \\
\hline \multirow[t]{2}{*}{ Others } & $0.355^{\star \star \star}$ & $0.765^{\star \star \star}$ & $0.168^{\star \star \star}$ & -0.095 & $-0.533^{\star \star \star}$ & 0.030 & $-0.637 *$ & -0.100 & -0.249 & 0.407 \\
\hline & $(0.070)$ & $(0.077)$ & $(0.057)$ & $(0.063)$ & $(0.138)$ & $(0.361)$ & $(0.353)$ & $(0.371)$ & $(0.447)$ & $(0.871)$ \\
\hline \multirow[t]{2}{*}{ Wealth index } & -0.004 & $0.137^{\star \star \star}$ & $0.086^{* \star \star}$ & $0.053^{\star \star \star}$ & $0.193 * \star \star$ & -0.028 & -0.192 & -0.053 & -0.008 & -0.086 \\
\hline & $(0.018)$ & $(0.020)$ & $(0.017)$ & $(0.018)$ & $(0.030)$ & $(0.210)$ & $(0.199)$ & $(0.189)$ & $(0.241)$ & $(0.475)$ \\
\hline \multicolumn{11}{|l|}{$\begin{array}{l}\text { Place of } \\
\text { residence }\end{array}$} \\
\hline \multicolumn{11}{|l|}{ Urban } \\
\hline \multirow[t]{2}{*}{ Rural } & $0.241^{\star \star \star}$ & $0.523^{\star \star \star}$ & 0.027 & $-0.282^{\star \star \star}$ & -0.131 & $-1.262^{\star}$ & 0.304 & $1.695^{\star}$ & 0.144 & -1.302 \\
\hline & $(0.061)$ & $(0.068)$ & $(0.055)$ & $(0.065)$ & $(0.099)$ & $(0.723)$ & 0.984) & $(0.923)$ & (1.139) & $(2.430)$ \\
\hline \multirow[t]{2}{*}{ Constant } & $-4.321 * \star \star$ & $-3.87 * \star \star$ & $-1.037^{\star \star \star}$ & 0.336 ** & 0.426 & $-11.677^{\star \star \star}$ & -6.495 & $-12.044^{\star \star \star}$ & $-10.286^{\star}$ & 2.286 \\
\hline & $(0.145)$ & $(0.166)$ & $(0.138)$ & $(0.162)$ & $(0.278)$ & $(4.289)$ & $(4.362)$ & $(4.633)$ & $(5.978)$ & (12.925) \\
\hline R square & 0.0423 & 0.0938 & 0.1361 & 0.1318 & 0.0456 & 0.211 & 0.247 & 0.3207 & 0.2267 & 0.174 \\
\hline Adj. R square & 0.0414 & 0.0929 & 0.1352 & 0.131 & 0.0446 & 0.127 & 0.167 & 0.2482 & 0.1443 & 0.0859 \\
\hline
\end{tabular}




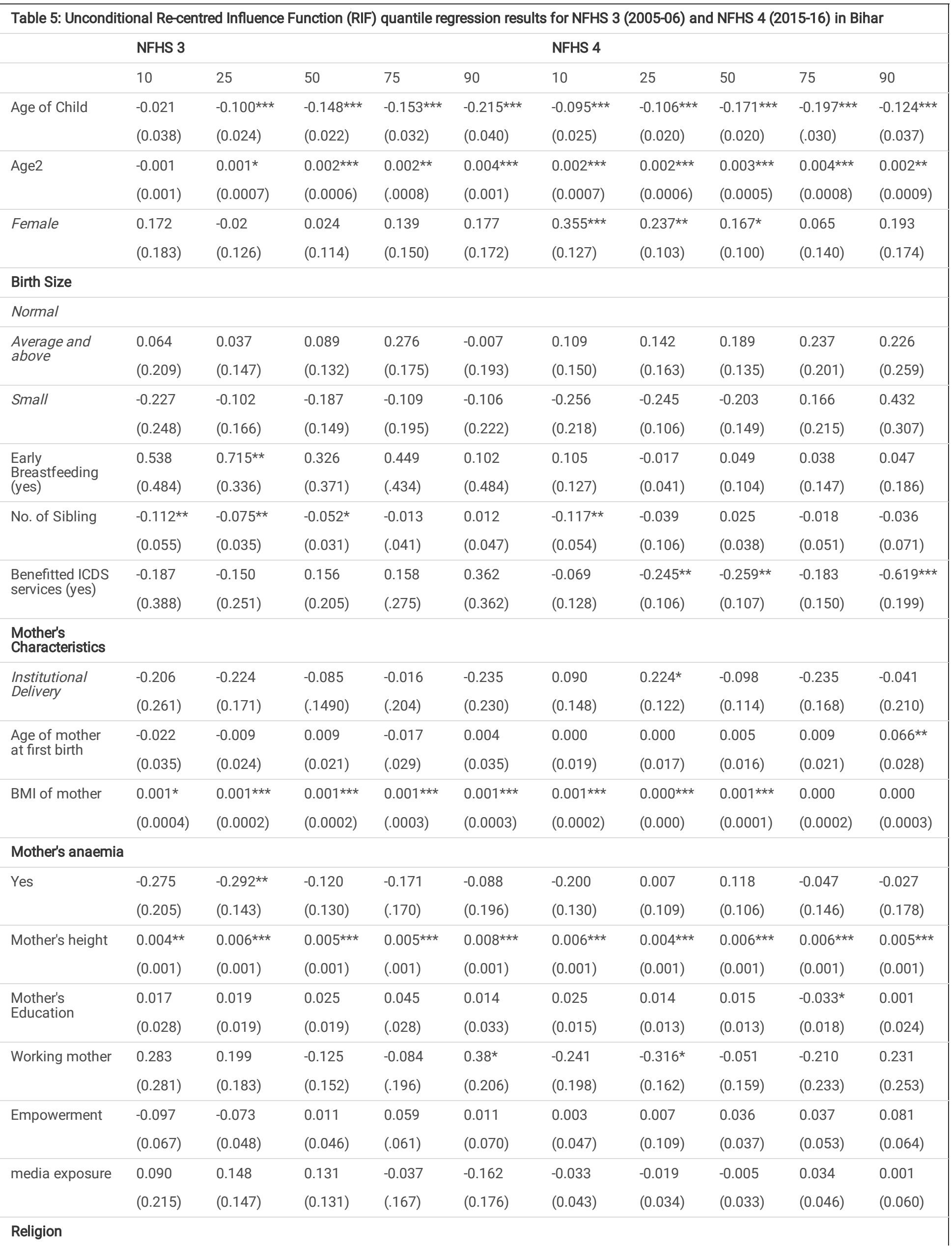




\begin{tabular}{|c|c|c|c|c|c|c|c|c|c|c|}
\hline \multicolumn{11}{|l|}{ Hindu } \\
\hline \multirow[t]{2}{*}{ Muslim/Others } & 0.187 & -0.015 & 0.108 & 0.286 & -0.290 & 0.035 & -0.099 & -0.118 & $-0.407 \star \star$ & -0.409 \\
\hline & $(0.245)$ & $(0.170)$ & $(0.157)$ & $(.216)$ & $(0.209)$ & $(0.162)$ & $(0.145)$ & $(0.141)$ & $(0.193)$ & $(0.253)$ \\
\hline \multicolumn{11}{|l|}{ Caste } \\
\hline \multicolumn{11}{|l|}{ SC } \\
\hline \multirow[t]{2}{*}{ ST } & 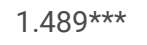 & 0.427 & 0.149 & -0.094 & -0.429 & 0.249 & 0.023 & 0.087 & -0.065 & -0.029 \\
\hline & $(0.494)$ & $(0.898)$ & $(0.707)$ & $(1.048)$ & $(0.411)$ & $(0.170)$ & $(0.130)$ & $(0.120)$ & $(0.174)$ & $(0.221)$ \\
\hline \multirow[t]{2}{*}{ Others } & 0.069 & 0.259 & $0.319 * \star$ & 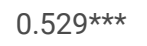 & $0.309 *$ & 0.305 & 0.146 & $0.369 \star *$ & 0.160 & -0.041 \\
\hline & $(0.275)$ & $(0.186)$ & $(0.160)$ & $(.179)$ & $(0.181)$ & $(0.212)$ & $(0.183)$ & $(0.182)$ & $(0.258)$ & $(0.329)$ \\
\hline \multirow[t]{2}{*}{ Wealth index } & $0.000 \star \star$ & $0.000 * \star$ & $0.000 * \star$ & $0.000 \star \star$ & 0.000 & 0.000 & 0.000 & $0.000 * \star$ & $0.000 * \star$ & 0.000 \\
\hline & $(0.000)$ & $(0.000)$ & $(0.000)$ & $(0.000)$ & $(0.000)$ & $(0.000)$ & $(0.000)$ & $(0.000)$ & $(0.000)$ & $(0.000)$ \\
\hline \multicolumn{11}{|c|}{ Place of residence } \\
\hline \multicolumn{11}{|l|}{ Urban } \\
\hline \multirow[t]{2}{*}{ Rural } & 0.207 & 0.023 & 0.006 & 0.265 & 0.085 & -0.177 & -0.089 & -0.132 & -0.173 & 0.101 \\
\hline & $(0.197)$ & $(0.136)$ & $(0.138)$ & $(.1940)$ & $(0.224)$ & $(0.194)$ & $(0.170)$ & $(0.170)$ & $(0.250)$ & $(0.297)$ \\
\hline \multirow[t]{2}{*}{ Constant } & $-9.868 * \star \star$ & $-12.311^{\star \star \star}$ & $-9.598 * \star \star$ & $-9.526 * \star \star$ & $-11.783^{\star \star \star}$ & 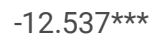 & $-8.243^{\star \star \star}$ & $-9.426 * \star \star *$ & $-7.241^{\star \star \star}$ & $-6.973 * \star *$ \\
\hline & (3.174) & $(1.948)$ & $(1.762)$ & $(2.390)$ & $(2.836)$ & (2.092) & $(1.664)$ & $(1.656)$ & (1.983) & $(2.338)$ \\
\hline R square & 0.090 & 0.171 & 0.209 & 0.176 & 0.124 & 0.061 & 0.094 & 0.177 & 0.115 & 0.062 \\
\hline Adj. R square & 0.072 & 0.155 & 0.193 & 0.159 & 0.107 & 0.049 & 0.083 & 0.167 & 0.104 & 0.050 \\
\hline
\end{tabular}

${ }^{* * *} p<0.001 ; * * p<0.01 ;{ }^{*} p<0.05$; Source: Computed by the authors from unit-level data of NFHS 3 and NFHS 4; Values in parenthesis are standard errors 


\begin{tabular}{|c|c|c|c|c|c|c|c|c|c|c|}
\hline & & \multicolumn{2}{|l|}{10} & \multicolumn{2}{|l|}{25} & \multicolumn{2}{|l|}{50} & \multicolumn{2}{|l|}{75} & 90 \\
\hline NFHS 1 HAZ score & & \multicolumn{2}{|l|}{$-4.935^{\star \star \star}$} & \multicolumn{2}{|l|}{$-3.870 * \star \star$} & \multicolumn{2}{|l|}{$-2.511^{\star \star \star}$} & \multicolumn{2}{|l|}{$-1.160 * \star \star$} & 0.098 \\
\hline NFHS 2 HAZ score & & \multicolumn{2}{|l|}{$-4.812^{\star \star \star}$} & \multicolumn{2}{|l|}{$-3.659 * \star \star$} & \multicolumn{2}{|l|}{$-2.339 * \star \star$} & \multicolumn{2}{|l|}{$-0.930 * \star \star$} & $0.455^{\star \star \star}$ \\
\hline \multicolumn{2}{|c|}{ Observed Raw gap in HAZ scores } & \multicolumn{2}{|l|}{-0.124} & \multicolumn{2}{|l|}{$-0.211 * \star *$} & \multicolumn{2}{|l|}{$-0.172^{\star *}$} & \multicolumn{2}{|l|}{$-0.230 * *$} & $-0.358^{* * *}$ \\
\hline Covariate effect & & \multicolumn{2}{|l|}{$-0.059 *$} & \multicolumn{2}{|l|}{-0.050} & \multicolumn{2}{|l|}{$-0.108^{\star \star}$} & \multicolumn{2}{|l|}{$-0.114^{\star \star \star}$} & -0.106 \\
\hline (\% contribution) & & \multicolumn{2}{|l|}{47.7} & \multicolumn{2}{|l|}{23.7} & \multicolumn{2}{|l|}{62.9} & \multicolumn{2}{|l|}{49.6} & 29.7 \\
\hline Coefficient Effect & & \multicolumn{2}{|l|}{-0.065} & \multicolumn{2}{|l|}{-0.161} & \multicolumn{2}{|l|}{-0.064} & \multicolumn{2}{|l|}{-0.116} & $-0.251^{\star}$ \\
\hline \multirow[t]{3}{*}{ (\%contribution) } & & \multicolumn{2}{|l|}{52.3} & \multicolumn{2}{|l|}{76.3} & \multicolumn{2}{|l|}{37.1} & 50.4 & & 70.3 \\
\hline & Covariate $\epsilon$ & ffect & & & & Co-efficier & effect & & & \\
\hline & 10 & 25 & 50 & 75 & 90 & 10 & 25 & 50 & 75 & 90 \\
\hline Aggregate effect & $-0.059 *$ & -0.050 & $-0.108^{\star \star}$ & $-0.114^{\star \star \star}$ & -0.106 & -0.065 & $-0.161^{\star}$ & -0.064 & -0.116 & $-0.251^{\star}$ \\
\hline Child Characteristics & $-0.193^{\star \star \star}$ & 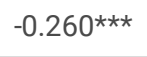 & $-0.261^{\star \star \star}$ & $-0.255^{\star \star \star}$ & -0.088 & 0.389 & 0.195 & 0.134 & $-0.818^{\star \star}$ & 0.342 \\
\hline$(\%)$ & 142.1 & 270.8 & 112.7 & 95.6 & 36.5 & -949.8 & -263.9 & -192.1 & 534.7 & -559.9 \\
\hline Mother's Characteristics & $-0.032^{\star \star}$ & $-0.037 \star \star$ & $-0.033^{\star}$ & -0.010 & 0.021 & -0.204 & -0.240 & -0.116 & 0.117 & -0.067 \\
\hline$(\%)$ & 23.6 & 38.4 & 14.1 & 3.6 & -8.8 & 498.0 & 324.5 & 166.3 & -76.4 & 110.1 \\
\hline $\begin{array}{l}\text { Household's } \\
\text { Characteristics }\end{array}$ & $0.105^{\star}$ & $0.235^{\star \star \star}$ & 0.064 & -0.021 & -0.186 & -0.102 & -0.059 & -0.162 & -0.021 & 0.126 \\
\hline$(\%)$ & -77.5 & -244.6 & -27.4 & 7.8 & 77.2 & 247.9 & 79.6 & 231.6 & 13.6 & -206.4 \\
\hline Spatial Characteristics & -0.016 & $-0.034 \star \star$ & -0.002 & 0.019 & 0.012 & 0.419 & -0.110 & -0.184 & -0.081 & -0.631 \\
\hline$(\%)$ & 11.9 & 35.8 & 0.9 & -7.1 & -4.8 & -1022.3 & 148.0 & 262.3 & 52.9 & 1033.8 \\
\hline Constant & & & & & & -0.543 & 0.139 & 0.258 & 0.649 & 0.169 \\
\hline Residuals & 0.077 & 0.047 & 0.124 & 0.153 & 0.135 & -0.024 & -0.087 & 0.006 & 0.037 & -0.19 \\
\hline Total & -0.136 & -0.096 & $-0.232^{\star \star}$ & $-0.267^{\star \star \star}$ & -0.241 & -0.041 & -0.074 & -0.07 & -0.153 & -0.061 \\
\hline
\end{tabular}

${ }^{* *} \mathrm{p}<0.001 ; *{ }^{*} \mathrm{p}<0.01 ;{ }^{*} \mathrm{p}<0.05$; Source: Computed by the authors from unit-level data of NFHS 1 and NFHS 2 


\begin{tabular}{|c|c|c|c|c|c|c|c|c|c|c|}
\hline & & \multicolumn{2}{|l|}{10} & \multicolumn{2}{|l|}{25} & \multicolumn{2}{|l|}{50} & \multicolumn{2}{|l|}{75} & 90 \\
\hline NFHS 2 HAZ score & & \multicolumn{2}{|c|}{ 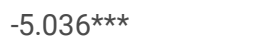 } & \multicolumn{2}{|c|}{$-4.043^{\star \star \star}$} & \multicolumn{2}{|l|}{$-2.908^{\star \star \star}$} & \multicolumn{2}{|l|}{$-1.294^{\star \star \star}$} & 0.474 \\
\hline NFHS 3 HAZ score & & \multicolumn{2}{|l|}{$-4.064^{\star \star \star}$} & \multicolumn{2}{|c|}{$-3.027^{\star \star \star}$} & \multicolumn{2}{|l|}{$-1.983^{\star \star \star}$} & \multicolumn{2}{|l|}{$-0.854^{\star \star \star}$} & 0.153 \\
\hline Observed Raw gap in $\mathrm{HA}$ & scores & \multicolumn{2}{|c|}{$-0.972 \star \star \star$} & \multicolumn{2}{|c|}{$-1.016 * \star \star *$} & \multicolumn{2}{|l|}{$-0.925 * \star \star$} & \multicolumn{2}{|l|}{$-0.440^{*}$} & 0.321 \\
\hline Covariate effect & & \multicolumn{2}{|l|}{-0.384} & \multicolumn{2}{|l|}{-0.112} & \multicolumn{2}{|l|}{0.393} & \multicolumn{2}{|l|}{0.68} & 0.991 \\
\hline (\% contribution) & & \multicolumn{2}{|l|}{39.5} & \multicolumn{2}{|l|}{11} & \multicolumn{2}{|l|}{-42.5} & \multicolumn{2}{|l|}{-154.5} & 309.3 \\
\hline Coefficient Effect & & \multicolumn{2}{|l|}{-0.588} & \multicolumn{2}{|l|}{$-0.905^{\star \star}$} & \multicolumn{2}{|l|}{$-1.317^{\star \star \star}$} & \multicolumn{2}{|l|}{$-1.121^{\star \star}$} & -0.671 \\
\hline \multirow[t]{3}{*}{ (\%contribution) } & & \multicolumn{2}{|l|}{60.5} & \multicolumn{2}{|l|}{89} & \multicolumn{2}{|l|}{142.5} & \multicolumn{2}{|l|}{254.5} & -209.3 \\
\hline & Covariat & effect & & & & Co-efficien & effect & & & \\
\hline & 10 & 25 & 50 & 75 & 90 & 10 & 25 & 50 & 75 & 90 \\
\hline Aggregate effect & -0.384 & -0.112 & 0.393 & 0.680 & 0.991 & -0.588 & $-0.905^{\star \star}$ & $-1.317 * \star \star$ & $-1.121^{\star \star}$ & -0.671 \\
\hline Child Characteristics & 0.034 & -0.032 & -0.207 & -0.415 & $-1.136^{\star *}$ & $-1.702^{\star \star \star}$ & $-1.667 \star \star \star$ & $-0.775^{\star \star \star}$ & $-0.897 \star \star \star$ & $-1.777 \star \star \star$ \\
\hline$(\%)$ & -2.2 & 2.2 & 90.1 & -418.8 & 397.3 & -136.4 & -150.9 & 181.0 & -1008.0 & -265.7 \\
\hline $\begin{array}{l}\text { Mother's } \\
\text { Characteristics }\end{array}$ & $-1.941^{*}$ & -1.409 & -0.349 & 0.630 & 1.811 & $9.36^{\star \star \star}$ & $22.151^{\star \star \star}$ & $6.782^{\star \star \star}$ & $6.046 * \star \star$ & $13.241 * \star *$ \\
\hline$(\%)$ & 123.4 & 98.8 & 151.9 & 636.3 & -633.4 & 750.1 & 2004.7 & -1584.5 & 6792.7 & 1979.2 \\
\hline $\begin{array}{l}\text { Household's } \\
\text { Characteristics }\end{array}$ & 0.114 & -0.300 & -0.151 & -0.058 & -0.352 & -0.102 & $-1.856^{\star \star \star}$ & -0.184 & $-0.373^{\star \star}$ & 0.020 \\
\hline$(\%)$ & -7.2 & 21.0 & 65.8 & -58.1 & 123.0 & -8.1 & -167.9 & 43.0 & -419.0 & 2.9 \\
\hline Spatial Characteristics & 0.220 & 0.314 & 0.478 & -0.058 & -0.610 & 0.214 & 0.163 & 0.192 & 0.284 & 0.232 \\
\hline$(\%)$ & -14.0 & -22.0 & -207.8 & -59.1 & 213.1 & 17.2 & 14.8 & -44.9 & 318.8 & 34.7 \\
\hline Constant & & & & & & $-6.524^{*}$ & $-17.687^{\star \star \star *}$ & $-6.443^{\star \star \star}$ & $-4.971 \star \star \star$ & $-11.046^{\star \star \star}$ \\
\hline Residuals & 1.189 & 1.315 & 0.623 & 0.581 & 1.278 & -1.836 & -2.009 & -0.889 & -1.209 & -1.34 \\
\hline Total & -1.573 & -1.427 & -0.23 & 0.099 & -0.286 & $1.248^{\star \star \star}$ & $1.105^{\star \star \star}$ & $-0.428^{\star \star \star *}$ & 0.089 & $0.669 * \star \star *$ \\
\hline
\end{tabular}

${ }^{* * *} p<0.001 ; * * p<0.01 ;{ }^{*} p<0.05$; Source: Computed by the authors from unit-level data of NFHS 2 and NFHS 3 


\begin{tabular}{|c|c|c|c|c|c|c|c|c|c|c|}
\hline & & \multicolumn{2}{|l|}{10} & \multicolumn{2}{|l|}{25} & \multicolumn{2}{|l|}{50} & \multicolumn{2}{|l|}{75} & 90 \\
\hline NFHS 2 HAZ score & & \multicolumn{2}{|l|}{$-4.041^{\star \star \star}$} & \multicolumn{2}{|l|}{$-3.016^{\star \star \star}$} & \multicolumn{2}{|l|}{$-1.975^{\star \star \star}$} & \multicolumn{2}{|l|}{$-0.843^{\star \star \star}$} & $0.166^{\star \star}$ \\
\hline NFHS 3 HAZ score & & \multicolumn{2}{|l|}{$-3.593^{\star \star \star}$} & \multicolumn{2}{|l|}{$-2.654^{\star \star \star}$} & \multicolumn{2}{|l|}{$-1.664^{\star \star *}$} & \multicolumn{2}{|l|}{-0.463} & $0.699 * * *$ \\
\hline Observed Raw gap in HAZ & cores & \multicolumn{2}{|l|}{$-0.448 * * *$} & \multicolumn{2}{|l|}{$-0.361 * * *$} & \multicolumn{2}{|l|}{$-0.311 * * *$} & \multicolumn{2}{|l|}{$-0.380 * * *$} & $-0.533 * * *$ \\
\hline Covariate effect & & \multicolumn{2}{|l|}{-0.206} & \multicolumn{2}{|l|}{0.061} & \multicolumn{2}{|l|}{0.168} & \multicolumn{2}{|l|}{0.261} & 0.026 \\
\hline (\% contribution) & & \multicolumn{2}{|l|}{45.9} & \multicolumn{2}{|l|}{-17.0} & \multicolumn{2}{|l|}{-53.9} & \multicolumn{2}{|l|}{ 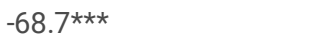 } & -4.9 \\
\hline Coefficient Effect & & \multicolumn{2}{|l|}{-0.243} & \multicolumn{2}{|l|}{$-0.423^{\star \star}$} & \multicolumn{2}{|l|}{$-0.479 * * *$} & \multicolumn{2}{|l|}{-0.642} & $-0.559 * \star$ \\
\hline \multicolumn{2}{|l|}{ (\%contribution) } & \multicolumn{2}{|l|}{54.1} & \multicolumn{2}{|l|}{117.0} & \multicolumn{2}{|l|}{153.9} & \multicolumn{2}{|l|}{168.7} & 104.9 \\
\hline & Covaria & effect & & & & Co-efficien & effect & & & \\
\hline & 10 & 25 & 50 & 75 & 90 & 10 & 25 & 50 & 75 & 90 \\
\hline Aggregate effect & -0.206 & 0.061 & 0.168 & 0.266 & 0.029 & -0.243 & $-0.423^{\star \star}$ & $-0.479 \star \star \star$ & $-0.646 * \star \star$ & -0.562 \\
\hline Child Characteristics & 0.424 & 0.220 & -0.412 & $1.088^{* \star \star}$ & $0.940 * \star$ & $0.429 *$ & $0.849 \star \star \star$ & $3.344^{\star \star \star}$ & $0.650 * \star$ & $1.349 * \star \star$ \\
\hline$(\%)$ & 140.5 & -21.2 & 16.1 & 25.4 & 107.5 & 2873.0 & 256.0 & 247.2 & -52.1 & -449.1 \\
\hline Mother's Characteristics & $0.456^{\star}$ & -0.463 & -1.319 & $1.041^{\star \star \star}$ & -0.160 & $6.123^{* \star \star}$ & -2.277 & $-18.339 * \star \star$ & $10.574^{\star \star \star}$ & 2.242 \\
\hline$(\%)$ & 151.2 & 44.6 & 51.5 & 24.3 & -18.3 & 41039.2 & -687.0 & -1355.7 & -847.8 & -746.3 \\
\hline $\begin{array}{l}\text { Household's } \\
\text { Characteristics }\end{array}$ & -0.582 & -0.789 & -0.849 & $2.145^{\star \star \star}$ & -0.200 & $-0.935^{\star \star \star}$ & $-0.958 * \star$ & $-1.711^{\star}$ & $0.733^{*}$ & -0.016 \\
\hline$(\%)$ & -192.9 & 76.1 & 33.2 & 50.1 & -22.9 & -6268.0 & -289.0 & -126.5 & -58.7 & 5.3 \\
\hline Spatial Characteristics & 0.004 & -0.005 & 0.020 & 0.008 & 0.014 & 0.076 & -0.246 & $0.906^{\star \star}$ & 0.163 & $0.816^{\star \star \star}$ \\
\hline$(\%)$ & 1.2 & 0.5 & -0.8 & 0.2 & 1.6 & 510.8 & -74.3 & 66.9 & -13.1 & -271.5 \\
\hline Constant & & & & & & $-5.678 * \star$ & 2.965 & $17.154 \star \star$ & 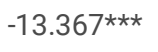 & -4.692 \\
\hline Residuals & -0.507 & 1.099 & 2.728 & -4.015 & -0.846 & -0.258 & -0.754 & -1.831 & 0.601 & -0.262 \\
\hline Total & 0.302 & -1.037 & -2.560 & $4.281^{\star \star \star}$ & 0.874 & 0.015 & 0.332 & 1.353 & $-1.247 * \star \star$ & -0.300 \\
\hline
\end{tabular}

${ }^{* *} p<0.001 ; * * p<0.01 ;{ }^{*} p<0.05$; Source: Computed by the authors from unit-level data of NFHS 3 and NFHS 4

\section{Supplementary Files}

This is a list of supplementary files associated with this preprint. Click to download.

- Appendix.doc 